\title{
The intracerebral hemorrhage acutely decreasing arterial pressure trial II (ICH ADAPT II) protocol
}

\author{
Laura Gioia ${ }^{1}$, Ana Klahrr', Mahesh Kate ${ }^{1}$, Brian Buck¹, Dariush Dowlatshahi ${ }^{2}$, Thomas Jeerakathil', Derek Emery ${ }^{3}$ \\ and Kenneth Butcher ${ }^{1 *}$ (D)
}

\begin{abstract}
Background: Aggressively lowering blood pressure (BP) in acute intracerebral hemorrhage (ICH) may improve outcome. Although there is no evidence that BP reduction changes cerebral blood flow, retrospective magnetic resonance imaging (MRI) studies have demonstrated sub-acute ischemic lesions in ICH patients. The primary aim of this study is to assess ischemic lesion development in patients randomized to two different BP treatment strategies. We hypothesize aggressive BP reduction is not associated with ischemic injury after $\mathrm{ICH}$.

Methods: The Intracerebral Hemorrhage Acutely Decreasing Blood Pressure Trial II (ICH ADAPT II) is a phase II multi-centre randomized open-label, blinded-endpoint trial. Acute ICH patients $(N=270)$ are randomized to a systolic blood pressure (SBP) target of $<140$ or $<180 \mathrm{mmHg}$. Acute ICH patients within $6 \mathrm{~h}$ of onset and two SBP measurements $\geq 140 \mathrm{mmHg}$ recorded $>2$ mins apart qualify. SBP is managed with a pre-defined treatment protocol. Patients undergo MRI at 48 h, Days 7 and 30, with clinical assessment at Day 30 and 90 . The primary outcome is diffusion weighted imaging (DWI) lesion frequency at $48 \mathrm{~h}$. Secondary outcomes include cumulative DWI lesion rate frequency within 30 days, absolute hematoma growth, prediction of DWI lesion incidence, 30-day mortality rates, day 90 functional outcome, and cognitive status.
\end{abstract}

Discussion: This trial will assess the impact of hypertensive therapies on physiological markers of ischemic injury. The findings of this study will provide evidence for the link, or lack thereof, between BP reduction and ischemic injury in $\mathrm{ICH}$ patients.

Trial registration: This study is registered with clinicaltrials.gov (NCT02281838, first received October 29, 2014).

Keywords: Blood Pressure, Intracerebral Hemorrhage, DWI, MRI, Stroke, Clinical Trial

\section{Background}

Acute management of elevated blood pressure (BP) in acute intracerebral hemorrhage $(\mathrm{ICH})$ remains an area of clinical equipoise. Phase III studies have failed to demonstrate marked improvements in clinical outcome when BP is lowered aggressively [1, 2]. The most recent trial demonstrated a trend to worse outcomes in patients in whom BP was lowered to $120-140 \mathrm{mmHg}$ [2]. Although aggressive $\mathrm{BP}$ reduction has not been associated with lower cerebral perfusion [3], magnetic resonance imaging (MRI)

\footnotetext{
* Correspondence: ken.butcher@ualberta.ca

${ }^{1}$ Division of Neurology, University of Alberta, 7th Floor Clinical Sciences

Building, 11350-83rd Avenue, Edmonton, AB T6G 2B7, Canada

Full list of author information is available at the end of the article
}

studies have reported acute and subacute ischemic lesions in $14-41 \%$ of ICH patients [4-9]. These lesions have been associated with aggressive BP treatment as well as unfavorable clinical outcomes but these data are all retrospective $[4,5,9]$. Therefore, we designed a prospective randomized study to definitively determine whether acute $\mathrm{BP}$ reduction is associated with an elevated risk of ischemic injury, detected with diffusion-weighted imaging (DWI).

\section{Methods \\ Study design \\ The Intracerebral Hemorrhage Acutely Decreasing Ar- terial Pressure Trial II (ICH ADAPT II) is a phase II multi-center prospective, randomized, open-label study}


with blinded-evaluation (PROBE). Eligible ICH patients are randomized 1:1 to systolic BP (SBP) targets of $<140$ or $<180 \mathrm{mmHg}$ (Fig. 1). This study is registered with clinicaltrials.gov (NCT02281838). The primary study aim is to assess DWI lesion frequency in patients randomized to aggressive versus conservative BP targets.

\section{Patient population}

Inclusion criteria

- Patients $\geq 18$ years with spontaneous ICH $\leq 6 \mathrm{~h}$ from onset

- Two SBP measurements $\geq 140 \mathrm{mmHg}$ recorded $>2$ min apart

- Hematoma volume on CT $<90 \mathrm{~mL}$, as estimated using the $\mathrm{ABC} / 2$ method [10]

- Onset $\leq 6 \mathrm{~h}$ prior to randomization

- Glasgow Coma Scale (GCS) $\geq 5$ prior to randomization

\section{Exclusion criteria}

- Definite contraindication to BP reduction (i.e. severe arterial stenosis, MoyaMoya disease)

- Definite indication for BP reduction (i.e. hypertensive encephalopathy or aortic dissection)

- Contraindication to MRI (i.e. cardiac pacemaker)

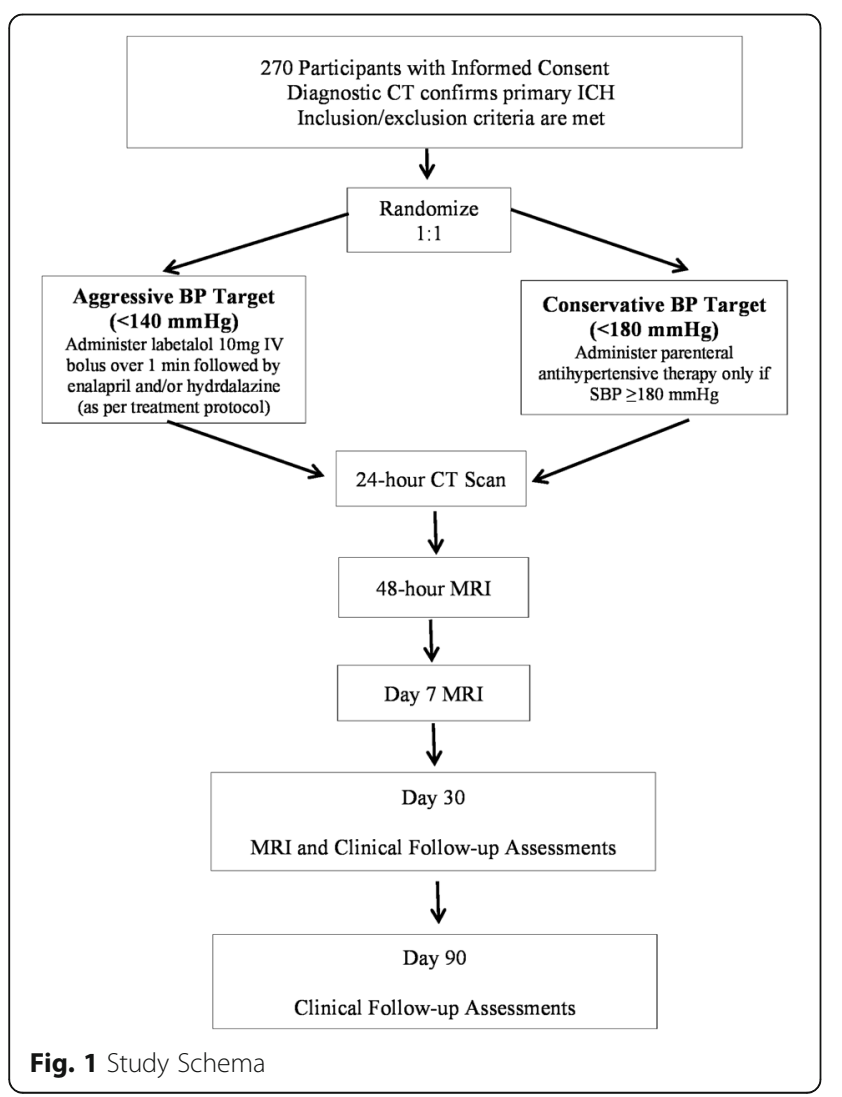

- Suspected secondary cause of ICH

- Ischemic stroke $<90$ days

- Planned hematoma resection

- Pre-morbid modified Rankin score (mRS) $\geq 3$

- Life expectancy $<6$ months

- Early implementation of palliative care

\section{Randomization}

All patients undergo standard screening assessments including BP, GCS, and National Institutes of Health Stroke Scale (NIHSS) scores prior to randomization (Table 1). A centralized web-based randomization process is used to assign BP treatment target.

\section{Interventions}

\section{BP Management}

The assigned BP target is achieved and maintained using an intravenous antihypertensive drug bolus protocol (Table 2). Patients in the aggressive BP target (SBP $<140 \mathrm{mmHg}$ ) group immediately receive a $10 \mathrm{mg}$ intravenous (IV) bolus of labetalol, followed by repeated boluses designed to lower systolic BP to $<140 \mathrm{mmHg}$ within $60 \mathrm{~min}$ of randomization. The protocol utilizes IV enalapril and hydralazine boluses as well.

Patients randomized to the conservative arm (SBP $<180 \mathrm{mmHg}$ group) are treated with antihypertensive agents only if $\mathrm{SBP} \geq 180 \mathrm{mmHg}$. BP and heart rate (HR) are continuously monitored non-invasively for the first $24 \mathrm{~h}$.

\section{Imaging Procedures}

Baseline: Diagnostic non-contrast computed tomography (CT) scan. This consists of $5 \mathrm{~mm}$ slices, no gap (120 kvp, $300 \mathrm{~mA}$ per slice) through the entire brain (18-20 slices with a $512 \times 512$ matrix).

24-h: Repeat CT scan at $24 \pm 3 \mathrm{~h}$ to assess for hematoma expansion and peri-hematoma edema volume.

48-h: MRI at $48 \pm 12 \mathrm{~h}$, including a T1-weighted sagittal localizer, T2-weighted images, DWI (the primary endpoint), Fluid-attenuated Inverse Recovery (FLAIR), Susceptibility Weighted Imaging (SWI), and pulse Arterial Spin Labeling (ASL; optional sequence). DWI sequences are combined to form isotropic (trace) diffusion images and Apparent Diffusion Coefficient (ADC) maps are generated from these raw data. ADC maps are used to ensure all lesions represent true diffusion restriction and not T2 shine through effects. FLAIR sequences are also utilized to assess chronic small vessel ischemic changes. SWI sequences are used to assess the burden (number, total volume and topography) of cerebral microbleeds. Pulse ASL data is used to generate blood flow maps to determine if DWI lesions are correlated with hypoperfusion. All image analyses are completed centrally by raters blinded to BP treatment group allocation. 
Table 1 Summary of trial procedures

\begin{tabular}{|c|c|c|c|c|c|c|}
\hline & Screening/Randomization & $24 \pm 3 \mathrm{~h}$ & $48 \pm 12 \mathrm{~h}$ & Day $7 \pm 2$ & Day $30 \pm 5$ & Day $90 \pm 30$ \\
\hline Eligibility Criteria & $\square$ & & & & & \\
\hline Signed Informed Consent & $\square$ & & & & & \\
\hline Past Medical History & $\square$ & & & & & \\
\hline Vital Signs (BP, HR) Monitoring & $\square$ & $\square$ & $\square$ & $\square$ & $\square$ & $\square$ \\
\hline Medications & $\square$ & & & $\square$ & $\square$ & $\square$ \\
\hline CT scan & $\square$ & $\square$ & & & & \\
\hline MRI scan & & & $\square$ & $\square$ & $\square$ & \\
\hline NIHSS & $\square$ & $\square$ & $\square$ & $\square$ & $\square$ & $\square$ \\
\hline Glasgow Coma Scale & $\square$ & $\square$ & $\square$ & $\square$ & $\square$ & $\square$ \\
\hline Modified Rankin Scale & $\square$ & & & $\square$ & $\square$ & $\square$ \\
\hline Montreal Cognitive Assessment & $\square$ & & & $\square$ & $\square$ & $\square$ \\
\hline Barthel Index, EuroQOL & & & & & $\square$ & $\square$ \\
\hline AE/SAE Reporting & & $\square$ & $\square$ & $\square$ & $\square$ & $\square$ \\
\hline End of Study Report & & & & & & $\square$ \\
\hline
\end{tabular}

Days 7 and 30: MRI repeat at Days $7 \pm 2$ and $30 \pm 5$ to assess for new DWI lesion development and evolution of those previously identified.

\section{Clinical assessments}

In-hospital clinical assessments $(24 \mathrm{~h}, 48 \mathrm{~h}$, day 7 and hospital discharge) of neurological deterioration are performed using GCS and NIHSS. Discharge mRS scores is obtained to assess disability and Montreal Cognitive Assessment (MoCA) to determine cognitive changes. This latter assessment is relevant as development of DWI lesions may impair cognition in ICH patients. All neurological, disability, and cognitive assessments are repeated at days 30 and 90 .

\section{Primary outcome}

The primary endpoint is DWI lesion frequency on the 48-h MRI, which is the time point DWI lesions have most commonly been observed after ICH [4-9]. This is also the time point most relevant to acute $\mathrm{BP}$ reduction.

\section{Secondary outcomes}

- Hematoma growth at $24 \mathrm{~h}$

- Hypothesis: The mean hematoma growth will be smaller in the SBP $<140 \mathrm{mmHg}$ group.

- Cumulative DWI lesion rate frequency within 30 days

- Hypothesis: The rate of DWI lesion development will be higher in the SBP $<140 \mathrm{mmHg}$ group.

- Day 30 mortality rates

- Hypothesis: DWI lesion development will predict mortality, which should be independent of BP randomization.

- Day 90 mRS scores
- Hypothesis: Median mRS will be positively correlated with number of DWI lesions.

- Day $90 \mathrm{MoCA}$

- Hypothesis: MoCA scores will be lower in patients with DWI lesions.

\section{Data safety monitoring body (DSMB)}

The DSMB (Additional file 1) reviews the proportion of patients with neurological deterioration within $48 \mathrm{~h}$ (defined as an increase in NIHSS $\geq 4$ points), 90-day mortality and all serious adverse events (SAE) after 33\% and $67 \%$ of patients are enrolled. The committee may modify or stop the trial at any point.

\section{Sample size estimates}

The sample size is based on an observed DWI lesion frequency of $26 \%$ in the $<180 \mathrm{mmHg}$ target group [4-9]. The odds ratio for DWI lesion occurrence is 1.03 per decrease in $\mathrm{mmHg}$ of mean arterial pressure (MAP) between baseline and the MRI scan [5]. In ICH ADAPT I, MAP in the aggressive treatment group decreased by an average of $28 \mathrm{mmHg}$ at the time of the primary endpoint assessment. Assuming a similar treatment effect in ICH ADAPT II, the predicted effect of SBP reduction $<140 \mathrm{mmHg}$ is an odds ratio of DWI lesion incidence of 1.84 . The trial has been powered to detect a 0.84 (relative) increase in the frequency of DWI lesions in the $<140 \mathrm{mmHg}$ target group. The predicted absolute increase in the proportion of patients with DWI lesions is $22 \%$.

Hypotheses:

$\mathrm{H}_{0}$ : The proportion of patients with DWI lesions in the $<140 \mathrm{mmHg}$ treatment arm will be $\leq 0.48$. 
Table 2 Acute BP treatment protocols

\begin{tabular}{|c|c|}
\hline \multicolumn{2}{|c|}{ A. $<140 \mathrm{mmHg}$ Target Group } \\
\hline & $\begin{array}{l}\text { Target SBP }<140 \mathrm{mmHg} \text { within } 30 \\
\text { min of randomization }\end{array}$ \\
\hline Monitoring & $\begin{array}{l}\text { - Record } \mathrm{BP} / \mathrm{HR} \mathrm{q}^{\mathrm{a}} 5 \mathrm{~min} \text { during active } \\
\text { treatment; } \mathrm{q} 15 \mathrm{~min} \times 1 \mathrm{~h}, \mathrm{q} 30 \mathrm{~min} \times 5 \mathrm{~h} \\
\text { and } \mathrm{q} 1 \mathrm{~h} \times 18 \mathrm{~h}\end{array}$ \\
\hline Labetalol (IV) & $\begin{array}{l}\text { - Labetalol test dose: } 10 \mathrm{mg} \text { bolus } \\
\text { over } 1 \mathrm{~min} \\
\text { - If } \mathrm{SBP} \geq 140 \mathrm{mmHg} \text { and HR }>55 \mathrm{BPM} \text {, } \\
\text { repeat } 10 \mathrm{mg} \text { bolus in } 5 \mathrm{~min} \text {. } \\
\text { - } 10-20 \mathrm{mg} \text { IV push q5 min until } \\
\text { SBP }<140 \mathrm{mmHg} \text { or HR }<55 \mathrm{BPM} \\
\text { - Maximum labetalol dose: } 300 \mathrm{mg} / 24 \mathrm{~h}\end{array}$ \\
\hline $\begin{array}{l}\text { And Enalapril (IV) (If } \\
\text { available) }\end{array}$ & - Enalapril 1.25 mg bolus \\
\hline And/or Hydralazine (IV) & $\begin{array}{l}\text { If } \mathrm{BP} \text { persistently }>140 \mathrm{mmHg} \text { : } \\
\text { - Hydralazine test dose: } 5 \mathrm{mg} \text { IV bolus } \\
\text { over } 1 \mathrm{~min} \\
\text { - If } \mathrm{SBP} \geq 140 \mathrm{mmHg} \text {, repeat } 5 \mathrm{mg} \text { IV } \\
\text { bolus in } 5 \mathrm{~min} \\
\text { - } 10-20 \mathrm{mg} \mathrm{IV} \text { bolus q } 5 \mathrm{~min} \text { until } \\
\text { SBP }<140 \mathrm{mmHg} \\
\text { - Maximum hydralazine dose }=240 \mathrm{mg} / 24 \mathrm{~h}\end{array}$ \\
\hline $\begin{array}{l}\text { Continuous IV Infusions } \\
\text { (ICU admission) }\end{array}$ & $\begin{array}{l}\text { If BP persistently > } 140 \mathrm{mmHg} \text { : } \\
\text { - Labetalol infusion } 2-8 \mathrm{mg} / \mathrm{min} \\
\text { (maximum } 300 \mathrm{mg} / 24 \mathrm{~h} \text { ) and/or } \\
\text { hydralazine infusion } 50-150 \mu \mathrm{g} / \mathrm{min}\end{array}$ \\
\hline
\end{tabular}

Maintenance Therapy

Maintain SBP $<140 \mathrm{mmHg} \times 24 \mathrm{~h}$ minimum

IV treatment prn ${ }^{\mathrm{b}} \quad$ If SBP $>140 \mathrm{mmHg}$ at any point:

- Labetalol (10-20 mg) / hydralazine (10-20 mg) boluses. Record BP/HR 5 and 15 min later

- Enalapril $1.25 \mathrm{mg} \mathrm{q} 6 \mathrm{~h}$ if SBP $>140 \mathrm{mmHg}$

- If $\mathrm{SBP} \leq 135 \mathrm{mmHg}$ or HR $<55 \mathrm{BPM}$, hold maintenance dose

B. $<180 \mathrm{mmHg}$ Target Group

Protocol to be used only if SBP $\geq 180 \mathrm{mmHg}$

\begin{tabular}{|c|c|}
\hline Monitoring & - as listed above \\
\hline Labetalol (IV) & $\begin{array}{l}\text { - Labetalol test dose: } 10 \mathrm{mg} \text { bolus over } 1 \mathrm{~min} \\
\text { - If } \mathrm{SBP} \geq 180 \mathrm{mmHg} \text { and } \mathrm{HR}>55 \mathrm{BPM} \text {, } \\
\text { repeat } 10 \mathrm{mg} \text { bolus in } 5 \mathrm{~min} \text {. } \\
\text { - } 10-20 \mathrm{mg} \text { IV push q5 min until } \\
\text { SBP }<180 \mathrm{mmHg} \text { or HR }<55 \mathrm{BPM} \\
\text { - Maximum labetalol dose: } 300 \mathrm{mg} / 24 \mathrm{~h}\end{array}$ \\
\hline Hydralazine (IV) & $\begin{array}{l}\text { If } \mathrm{BP} \text { persistently }>180 \mathrm{mmHg} \text { : } \\
\text { - Hydralazine test dose: } 5 \mathrm{mg} \text { IV bolus } \\
\text { over } 1 \mathrm{~min} \\
\text { - If } \mathrm{SBP} \geq 180 \mathrm{mmHg} \text {, repeat } 5 \mathrm{mg} \mathrm{IV} \\
\text { bolus in } 5 \mathrm{~min} \\
\text { - } 10-20 \mathrm{mg} \mathrm{IV} \text { bolus q } 5 \mathrm{~min} \text { until } \\
\text { SBP }<180 \mathrm{mmHg} \\
\text { - Maximum hydralazine dose }=240 \mathrm{mg} / 24 \mathrm{~h}\end{array}$ \\
\hline \multicolumn{2}{|c|}{ Maintenance Therapy } \\
\hline IV treatment prn & $\begin{array}{l}\text { If } \mathrm{SBP}>180 \mathrm{mmHg} \text { at any point during } 24 \mathrm{~h} \text { : } \\
\text { - Labetalol (10-20 mg)/ hydralazine } \\
\text { (10-20 mg) boluses. Record BP/HR } 5 \\
\text { and } 15 \mathrm{~min} \text { later }\end{array}$ \\
\hline
\end{tabular}

${ }^{\mathrm{a}} \mathrm{q}=$ every, ${ }^{\mathrm{b}} \mathrm{prn}=$ when necessary
$\mathrm{H}_{\mathrm{A}}$ : The proportion of patients with DWI lesions in the $<140 \mathrm{mmHg}$ treatment arm will be $>0.48$.

The primary analysis will be a one-sided test of proportions at the alpha $=0.025$ level. A sample size of 180 evaluable patients will be required to reject the null hypothesis with $80 \%$ power (alpha $=0.025$ ). To account for withdrawal of consent and missing data related to early death and MRI contraindications, the sample size has been increased to 270 patients.

\section{Statistical analyses}

The primary endpoint will be tested using Fisher's Exact test. There will be no interim analyses for efficacy or futility.

\section{Discussion}

Elevated BP has been associated with hematoma growth, mortality, and disability after ICH [11]. However, the most recent clinical trial data have revived concerns about the safety of very aggressive BP reduction [2]. It is unknown if this trend to worse outcome is related to cerebral ischemic changes, but it is one possible mechanism [12]. There are mixed data regarding the development of ischemic lesions after $\mathrm{ICH}$ and its association with BP. Retrospective studies have suggested that there is a negative, positive, and even no correlation between the two $[5,8,13,14]$.

The current trial utilizes a physiological endpoint that is more sensitive to ischemic injury to determine whether aggressive $\mathrm{BP}$ reduction in $\mathrm{ICH}$ patients exacerbates DWI lesion development, in individual patients. We have previously conducted a trial, ICH ADAPT I, in which ICH patients were randomized to aggressive (SBP $<150 \mathrm{mmHg}$ ) versus conservative (SBP $<180 \mathrm{mmHg}$ ) BP management strategies [3]. We did not find a difference in peri-hematoma cerebral blood flow (CBF) in these two groups. Most importantly, the magnitude of BP change was not related to regional CBF [3]. In contrast, several studies indicate that delayed cerebral ischemia, evident on MRI scan only, is common within the first week after ICH [4-9]. Although the majority of perihematoma DWI hyperintensities result from plasma derived edema,[15] true diffusion restriction representing bioenergetic compromise in this region and topographically remote areas are also present in some patients [4-9]. These DWI lesions tend to be small but are still a subject of concern as longitudinal studies indicate the probability of death/dependence at one year is increased between five and six-fold in these patients $[13,16]$.

Canadian Stroke Best Practices recommendations for hyperacute stroke care recognize the safety of aggressively reducing SBP [17]. Furthermore, current American Heart Association/American Stroke Association guidelines advise lowering SBP $<140 \mathrm{mmHg}$ given its potential 
to improve patient prognosis in $\mathrm{ICH}$ patients, but more aggressive treatment is not encouraged [18]. These recommendations are based primarily on the results of two phase III studies which have failed to demonstrate an increase in the proportion of patients with good clinical outcomes when BP is lowered aggressively $[1,2]$. In the Intensive Blood Pressure Reduction in Acute Cerebral Hemorrhage Trial (INTERACT II), 2839 ICH patients were randomized within $6 \mathrm{~h}$ of symptom onset to a SBP target of $<140$ or $<180 \mathrm{mmHg}$. The rate of death/disability was similar in the $<140 \mathrm{mmHg}$ target group (52\%) and the $<180 \mathrm{mmHg}$ target group (55.3\%; odds ratio with intensive treatment, $0.87 ; 95 \% \mathrm{CI}, 0.75$ to 1.01 ; $p=0.06$ ) [1]. In the Antihypertensive Treatment of Acute Cerebral Hemorrhage II (ATACH II), patients were randomized earlier (4.5 rather than $6 \mathrm{~h}$ after symptom onset) to the aggressive and conservative $\mathrm{BP}$ strategies [2]. This trial recruited $1000 \mathrm{ICH}$ patients, in which the primary outcome of death and disability (GCS >5) was observed in $38.7 \%$ vs. $37.7 \%$ in the aggressive vs. conservative treatment, respectively. The investigators concluded that aggressive antihypertensive therapy did not improve outcome.

At this point the optimal BP treatment strategy remains unknown. It has been hypothesized that an earlier intervention (e.g., in the prehospital setting) may be needed to improve patient prognosis, and small clinical trials have demonstrated the feasibility and safety of hyperacute BP management in stroke patients $[19,20]$. However, it may be that in some patients aggressive $\mathrm{BP}$ reduction precipitate and/or exacerbate ischemic lesion development. This can only be addressed with a randomized controlled trial specifically addressing this endpoint.

In conclusion, ICH ADAPT II will provide evidence for the link, or lack thereof, between BP reduction and ischemic injury. This will add support for the safety of early systolic BP reduction to $<140 \mathrm{mmHg}$, or alternatively a more nuanced approach to acute hypertension management in $\mathrm{ICH}$ patients.

\section{Additional files}

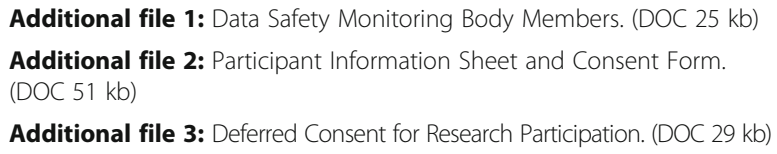

\section{Abbreviations}

ADC: Apparent diffusion coefficient; ASL: Arterial spin labeling; ATACH II: Antihypertensive treatment of acute cerebral hemorrhage II; BP: Blood pressure; CBF: Cerebral blood flow; CT: Computed tomography; DSMB: Data safety monitoring body; DWI: Diffusion-weighted imaging; FLAIR: Fluidattenuated inverse recovery; GCS: Glasgow coma scale; ICH ADAPT II: Intracerebral Hemorrhage Acutely Decreasing Blood Pressure Trial II;

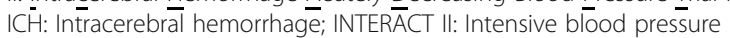
reduction in acute cerebral hemorrhage II; MAP: Mean arterial pressure;
MoCA: Montreal cognitive assessment; MRI: Magnetic resonance imaging; mRS: Modified Rankin scale; NIHSS: National Institutes of Health Stroke Scale; PROBE: Prospective, randomized, open-label study with blinded-evaluation; SAE: Serious adverse events; SBP: Systolic blood pressure; SWI: Susceptibility Weighted Imaging

\author{
Acknowledgements \\ Not applicable. \\ Funding \\ The trial is funded by the Heart and Stroke Foundation of Canada \\ (GIA G-14-0006004).
}

\section{Availability of data and materials}

Not applicable.

\section{Authors' contributions}

$L G, A K$, and $K B$ drafted the manuscript. $A K$ and $K B$ will be involved in the main data analysis. $L G, M K, B B, D D, T J, D E$, and $K B$ are involved in data collection. KB designed the trial and wrote the protocol. All authors read and approved the final manuscript.

\section{Competing interests}

The authors declare that they have no competing interests.

\section{Consent for publication \\ Not applicable.}

\section{Ethics approval and consent to participate}

This study is being conducted according to Canadian and international standards of Good Clinical Practice for all studies. Applicable government regulations and University of Alberta research policies and procedures are followed. This protocol and any amendments have been submitted and approved by the University of Alberta Health and Research Ethics Board. Informed consent (Additional file 2) is obtained from the patient, or substitute decision maker prior to randomization. A deferred consent (Additional file 3) procedure is used in cases where the patient is incapacitated and a surrogate decision maker is not immediately available to provide consent.

\section{Publisher's Note}

Springer Nature remains neutral with regard to jurisdictional claims in published maps and institutional affiliations.

\section{Author details}

'Division of Neurology, University of Alberta, 7th Floor Clinical Sciences Building, 11350-83rd Avenue, Edmonton, AB T6G 2B7, Canada. ${ }^{2}$ Division of Neurology, University of Ottawa, Ottawa, ON, Canada. ${ }^{3}$ Department of Diagnostic Imaging, University of Alberta, Edmonton, AB, Canada.

Received: 24 April 2017 Accepted: 10 May 2017

Published online: 19 May 2017

References

1. Anderson CS, Heeley E, Huang Y, Wang J, Stapf C, Delcourt C, et al. Rapid blood-pressure lowering in patients with acute intracerebral hemorrhage. $N$ Engl J Med. 2013;368:2355-65.

2. Qureshi Al, Palesch YY, Barsan WG, Hanley DF, Hsu CY, Martin RL, et al. Intensive Blood-Pressure Lowering in Patients with Acute Cerebral Hemorrhage. N Engl J Med. 2016;375(11):1033-43.

3. Butcher KS, Jeerakathil T, Hill M, Demchuk AM, Dowlatshahi D, Coutts SB, et al. The intracerebral hemorrhage acutely decreasing arterial pressure trial. Stroke. 2013;44(3):620-6.

4. Prabhakaran S, Gupta R, Ouyang B, John S, Temes RE, Mohammad Y, et al. Acute brain infarcts after spontaneous intracerebral hemorrhage: a diffusion-weighted imaging study. Stroke. 2010;41:89-94.

5. Menon RS, Burgess RE, Wing JJ, Gibbons MC, Shara NM, Fernandez S, et al. Predictors of highly prevalent brain ischemia in intracerebral hemorrhage. Ann Neurol. 2012;71:199-205.

6. Kang DW, Han MK, Kim HJ, Yun SC, Jeon SB, Bae HJ, et al. New ischemic lesions coexisting with acute intracerebral hemorrhage. Neurology. 2012;79:848-55. 
7. Gregoire SM, Charidimou A, Gadapa N, Dolan E, Antoun N, Peeters A, et al. Acute ischaemic brain lesions in intracerebral haemorrhage: multicentre cross-sectional magnetic resonance imaging study. Brain. 2011;134:2376-86.

8. Kimberly WT, Gilson A, Rost NS, Rosand J, Viswanathan A, Smith EE, et al. Silent ischemic infarcts are associated with hemorrhage burden in cerebral amyloid angiopathy. Neurology. 2009;72:1230-5.

9. Garg RK, Liebling SM, Maas MB, Nemeth AJ, Russell EJ, Naidech AM. Blood pressure reduction, decreased diffusion on MRI, and outcomes after intracerebral hemorrhage. Stroke. 2012;43:67-71.

10. Kothari RU, Brott T, Broderick JP, Barsan WG, Sauerbeck LR, Zuccarello M, et al. The ABCs of measuring intracerebral hemorrhage volumes. Stroke. 1996; 27(8):1304-5.

11. Butcher K, Laidlaw J. Current intracerebral haemorrhage management. J Clin Neurosci. 2003;10(2):158-67.

12. Prabhakaran $\mathrm{S}$, Naidech $\mathrm{AM}$. Ischemic brain injury after intracerebral hemorrhage: a critical review. Stroke. 2012;43(8):2258-63.

13. Singer OC, Kurre W, Humpich MC, Lorenz MW, Kastrup A, Liebeskind DS, et al. Risk assessment of symptomatic intracerebral hemorrhage after thrombolysis using DWI-Aspects. Stroke. 2009;40(8):2743-8.

14. Brazzelli M, Sandercock Peter AG, Chappell Francesca M, Celani Maria G, Righetti $\mathrm{E}$, Arestis N, et al. Magnetic resonance imaging versus computed tomography for detection of acute vascular lesions in patients presenting with stroke symptoms. Cochrane Database Syst Rev. 2009; doi:10.1002/ 14651858.CD007424.pub2.

15. Butcher KS, Baird T, MacGregor L, Desmond P, Tress B, Davis S. Perihematomal edema in primary intracerebral hemorrhage is plasma derived. Stroke. 2004;35(8):1879-85.

16. Murat Arsava E, Kayim-Yildiz O, Oguz KK, Akpinar E, Topcuoglu MA. Elevated Admission Blood Pressure and Acute Ischemic Lesions in Spontaneous Intracerebral Hemorrhage. J Stroke Cerebrovasc Dis. 2013;22(3):250-4.

17. Casaubon LK, Boulanger J, Blacquiere D, Boucher S, Brown K, Goddard T, et al. Canadian stroke best practice recommendations: hyperacute stroke care guidelines, update 2015. Int J Stroke. 2015;10(6):924-40,

18. Hemphill JC, Greenberg SM, Anderson CS, Becker K, Bendok BR, Cushman $M$, et al. Guidelines for the management of spontaneous intracerebral hemorrhage. Stroke. 2015;46(7):2032-60.

19. Shaw L, Price C, Mclure S, Howel D, Mccoll E, Younger P, et al. Paramedic Initiated Lisinopril For Acute Stroke Treatment ( PIL-FAST): results from the pilot randomised controlled trial. Emerg Med J. 2014;31(12)994-9.

20. Right T, Ankolekar S, Fuller M, Cross I, Renton C, Cox P, et al. Feasibility of an ambulance-based stroke trial, and safety of glyceryl trinitrate in ultra-acute stroke: the rapid intervention with glyceryl trinitrate in hypertensive stroke trial (RIGHT, ISRCTN66434824). Stroke. 2013;44:3120-8.

\section{Submit your next manuscript to BioMed Central and we will help you at every step:}

- We accept pre-submission inquiries

- Our selector tool helps you to find the most relevant journal

- We provide round the clock customer support

- Convenient online submission

- Thorough peer review

- Inclusion in PubMed and all major indexing services

- Maximum visibility for your research

Submit your manuscript at www.biomedcentral.com/submit

CBiomed Central 